\title{
SISTEM INFORMASI MANAJEMEN GUDANG OBAT MENGGUNAKAN DATABASE DAN FORM ORACLE DI PT. LEUWITEX
}

\author{
Aditya Sudiatmo \\ Program Studi Teknik Informatika, Sekolah Tinggi Teknologi Bandung \\ diditatmo@gmail.com
}

\begin{abstract}
Abstrak
Sistem informasi merupakan sebuah sarana yang digunakan untuk mendapatkan informasi secara lengkap dalam suatu periode tertentu. Informasi yang diberikan haruslah relevan dan akurat sehingga informasi tersebut dapat digunakan sebagai pengambilan keputusan bagi suatu instansi atau perusahaan. Saat ini perkembangan sistem informasi sangat pesat dan cepat, sehingga menjadi sebuah tantangan baru bagi sebuah perusahaan untuk memindahkan sistem manual kedalam sistem digital yang lebih sederhana dan memiliki kapasitas penyimpanan yang besar. Selain kapasitas yang harus dipertimbangkan, kinerja sistem informasi harus diperhitungkan agar dapat mengganti sistem yang bekerja manual kedalam sistem yang bekerja secara komputerisasi. Transaksi Gudang Obat Kecil di PT Leuwitex meliputi transaksi penerimaan, pengeluaran, balancing, stock opname, pelaporan persediaan, pelaporan transaksi keluar dan masuk, dan beberapa laporan lainnya. Seluruh transaksi yang dilakukan oleh Gudang Obat Kecil dilaporkan kepada pihak akunting. Permasalahan yang sering terjadi pada saat proses pelaporan yaitu keterlambatan pelaporan yang diakibatkan oleh beberapa hal, diantaranya perhitungan akumulasi transaksi yang manual, pencarian slip permintaan yang tertumpuk, penghitungan slip permintaan secara manual, pengelompokan transaksi secara manual, serta masih banyak lagi permasalahan yang dihadapi dalam proses pelaporan kepada pihak akunting. Sistem Informasi Manajemen Gudang Obat Kecil, merupakan sebuah inovasi yang diciptakan agar sistem transaksi manual dapat terekam secara digital dan dapat terlacak dengan waktu yang sangat singkat dan cepat. Selain itu, informasi yang dikeluarkan lebih cepat dan mudah untuk diolah kembali sesuai dengan kebutuhan pengguna secar menyeluruh.
\end{abstract}

Kata Kunci : Manajemen Gudang, Oracle Forms, Oracle Reports

\begin{abstract}
Information system is facilitation for get all information at some periode. Information has given must be relevan and acurate, so that information can be used for take a opportunity on instation or company. Today system information very fast grown up, and that case is a big challenge for company to migrate from manual system to a simple computerise system and must have a big capacity for save data. Computerise system must be faster than manual system. Small Medicine Warehouse transactions at PT Leuwitex include receipts, expenditures, balances, stock taking, inventory reporting, outgoing and incoming transaction reports, and several other reports. All transactions carried out by the Small Medicine Warehouse are reported to the accounting party. Problems that often occur in the reporting process are reporting delays caused by several things, including manual calculation of accumulated transactions, stacked request slips, manual calculation of request slips, manual grouping of transactions, and many other problems encountered in the reporting process. to the bookkeeper. Small Medicine Warehouse Management Information System, is an innovation created so that manual transaction systems can be recorded digitally and can be tracked in a very short and fast time. In addition, the information released is faster and easier to reprocess according to user needs as a whole.
\end{abstract}

Keyword: Warehouse Management, Oracle Forms, Oracle Reports

\section{PENDAHULUAN}

Sistem informasi merupakan sebuah sarana yang digunakan untuk mendapatkan informasi secara lengkap dalam suatu periode tertentu. Informasi yang diberikan haruslah relevan dan akurat sehingga informasi tersebut dapat digunakan sebagai pengambilan keputusan bagi suatu instansi atau perusahaan. Saat ini perkembangan sistem informasi sangat pesat dan cepat, sehingga menjadi sebuah tantangan baru bagi sebuah perusahaan untuk memindahkan sistem manual kedalam sistem digital yang lebih sederhana dan memiliki kapasitas penyimpanan yang besar. Selain kapasitas yang harus dipertimbangkan, kinerja sistem informasi harus diperhitungkan agar dapat mengganti sistem yang bekerja manual kedalam sistem yang bekerja secara komputerisasi. Transaksi Gudang Obat Kecil di PT Leuwitex meliputi transaksi penerimaan, pengeluaran, balancing, stock opname, pelaporan persediaan, pelaporan transaksi keluar dan masuk, dan beberapa laporan lainnya. Seluruh transaksi yang dilakukan oleh Gudang Obat Kecil dilaporkan kepada pihak akunting.

Permasalahan yang sering terjadi pada saat proses pelaporan yaitu keterlambatan pelaporan yang diakibatkan oleh beberapa hal, diantaranya perhitungan akumulasi transaksi yang manual, pencarian slip permintaan yang tertumpuk, penghitungan slip permintaan secara manual, pengelompokan transaksi secara manual, serta masih banyak lagi permasalahan yang dihadapi dalam proses pelaporan kepada pihak akunting.

Permasalahan yang terjadi tidak hanya berasal dari sisi Gudang Obat Kecil, tetapi tidak jarang permasalahan yang mengakibatkan proses pelaporan terhambat berasal dari area Produksi, dimana area Produksi melakukan pengambilan barang ke Gudang Obat Kecil tanpa menggunakan formulir permintaan, formulir permintaan hilang, jumlah obat yang diambil tidak sesuai dengan formulir permintaan, dan masih banyak lagi hal lainnya.

Permasalahan yang terjadi di Gudang Obat Kecil berdampak sangat besar terhadap laporan akunting, dimana laporan yang dihasilkan akan mengalami kemunduran hingga 15 hari disetiap bulannya yang diakibatkan oleh proses perhitungan formulir permintaan secara manual setiap harinya. Hal ini berarti sistem yang berjalan kurang efektif sehingga perlu dibenahi. Selain kurangnya efektifitas, sistem yang dijalankan kurang efisien dikarenakan setiap bulannya banyak 
P-ISSN: 2656-7377 || E-ISSN: 2714-8467

formulir permintaan yang perlu dicetak, kemudian tempat penyimpanan arsip formulir permintaan baik yang masih kosong maupun yang sudah dilakukan transaksi yang sangat besar.

\section{TINJAUAN PUSTAKA}

\section{Sistem}

Secara sederhana, suatu sistem dapat diartikan sebagai suatu kumpulan atau himpunan dari suatu unsur, komponen, atau variabel yang terorgabisir, saling berinteraksi, saling tergantung satu sama lain, dan terpadu. Teori sistem secara umum yang pertama kali diuraikan oleh Kenneth Boulding terutama menekankan pentingnya perhatian terhadap setiap bagian yang membentuk sebuah sistem[1].

Teori sistem melahirkan konsep-konsep futuristik, antara lain yang terkenal dengan konsep sibernatika (cybernetics). Konsep atau bidang kajian ilmiah ini terutama berkaitan dengan upaya menerapkan berbagai disiplin ilmu, yaitu perilaku, fisika, biologi, dan teknik. Oleh karena itu, sibernatika biasanya berkaitan dengan usaha-usaha otomasi tugas-tugas yang dilakukan oleh manusia sehingga melahirkan studi-studi tentang robotika, kecerdasan buatan (artificial intelengency), dan lain sebagainya. Unsur-unsur yang mewakili suatu sistem secara umum adalah masukan (input), pengolahan (processing), dan keluaran (output) [1].

Beberapa pengertian atau definisi mengenai sistem yang diberikan oleh para ahli sebagai bahan perbandingan antara lain sebagai berikut:

a. Sistem adalah satu kesatuan komponen yang saling terhubung dengan batasan yang jelas bekerja bersamasama untuk mencapai seperangkat tujuan[2].

b. Pengertian sistem adalah sekumpulan elemen yang saling terkait atau terpadu yang dimaksudkan untuk mencapau tujuan[3].

c. Ackof dan Effendy mengatakan bahwa sistem adalah setiap kesatuan, secara konseptual atau fisik, yang terdiri dari bagian-bagian dalam keadaan saling tergantung satu sama lain[4].

d. Dalam Kamus Besar Bahasa Indonesia disebutkan bahwa sistem mempunyai dua pengertian; (a) Seperangkat unusr yang secara teratur saling berkaitan sehingga membentuk suatu totalitas; dan (b) Susunan yang teratur dari pandangan, teori, asas, dan sebagainya[5].

e. Sistem menurut Mc Leod adalah sekelompok elemen-elemen yang terintegrasi dengan tujuan yang sama untuk mencapai tujuan. [6][7]

f. Menurut Jugiayanto terdapat dua kelompok pendekatan sistem didalam mendefinisikan sistem yaitu pendekatan pada prosedur dan pendekatan pada komponen-komponen dan elemen-elemen. [8][7]

Dari definisi-deifinisi diatas, terlihat bahwa masing-masing menekankan bahwa sistem memakai pendekatan pada elemen atau komponen. Artinya, bahwa sistem haruslah terdiri atas berbagai komponen/elemen yang saling berhubungan sehingga membentuk satu kesatuan yang utuh.

\section{Informasi}

Informasi merupakan data atau fakta yang telah diproses sedemikian rupa, sehingga berubah bentuknya menjadi informasi. Di samping itu informasi dapat mengurangi ketidakpastian serta mempunyai nilai dalam keputusan karena dengan adanya informasu kita dapat memilih tindakan-tindakan dengan resiko yang kecil[4].

Dalam pengertian lain, Informasi merupakan hasil dari pengolahan data, akan tetapi tidak semua hasil dari pengolahan tersebut bisa menjadi informasi, hasil pengolahan data yang tidak memberikan makna atau arti serta tidak bermanfaat bagi seseorang bukanlah merupakan infromasi bagi orang tersebut. Dari uraian tentang informasi ini ada 3 hal yang penting yang harus diperhatikan disini yaitu[7]:

a. Informasi merupakan hasil pengolahan data

b. Memberikan makna atau arti

c. Berguna atau bermanfaat dalam meningkatkan kepastian

\section{Sistem Informasi}

Pengertian sistem informasi menurut beberapa pakar yaitu, sebagai berikut[4]:

a. Sistem informasi dalam suatu pemahaman yang sederhana dapat didefinisikan sebagai satu sistem berbasis komputer yang menyediakan informasi bagi beberapa pemakai dengan kebutuhan yang serupa [9].

b. Sistem informasi adalah kombinasi dari people, hardware, software, jaringan komunikasi, sumber-sumber data, prosedur dan kebijakan yang terorganisasi dengan baik yang dapat menyimpan, mengadakan lagi, menyimpan dan menyebarluaskan informasi dalam suatu organisasi[2].

c. Menurut Alter dalam Effendy sistem informasi adalah kombinasi antara prosedur kerja, informasi, orang, dan teknologi informasi yang diorganisasikan untuk mencapai tujuan dalam sebuah organisasi.

d. Menurut Wilkinson, sistem informasi adalah kerangka kerja yang mengkoordinasikan sumber daya (manusia, komputer) untuk mengubah masukan.

\section{Sistem Informasi Manajemen}

Pada dasarnya orang dapat membahas sistem informasi manajemen tanpa komputer, tetapi kemampuan komputer membuat SIM terwujud. Persoalannya bukan dipakai atau tidaknya komputer dalam sebuah sistem informasi 
P-ISSN: 2656-7377 || E-ISSN: 2714-8467

manajemen, tetapi sejauh mana berbagai proses akan dikomputerisasikan. Dalam sebagian besar persoalan, manusia dan mesin membentuk sebuah sistem gabungan dengan hasil yang diperoleh melalui serangkaian dialog dan interaksi antara komputer dan seorang manusia pengolah. Istilah yang umum dikenal orang adalah sebuah sistem manusia/mesin yang terpadu untuk menyajikan informasi guna mendukung fungsi operasi organisasi, manajemen, dan proses pengambilan keputusan di dalam suatu organisasi. Sistem ini menggunakan perangkat keras (hardware) dan perangkat lunak (software)komputer, prosedur pedoman, model manajemen, dan keputusan serta sebuah bank/basis data yang disebut database.

Raymond McLeod Jr mengemukakan bahwa SIM adalah sebagai suatu sistem berbasis komputer yang menyediakan informasi bagi beberapa pemakai dengan kebutuhan serupa. Output informasi digunakan oleh manajer maupun non-manajer dalam perusahaan untuk membuat keputusan dalam memecahkan masalah[4].

\section{Basis Data}

Data merupakan fakta mengenai suatu objek seperti manusia, benda, peristiwa, konsep, keadaan dan sebagainya yang dapat dicatat dan mempunyai arti secara implisit. Data dapat dinyatakan dalam bentuk angka, karakter atau simbol, sehingga bila data dikumpulkan dan saling berhubungan maka dikenal dengan istilah basis data (database). Sedangkan menurut George Tsu-der Chou basis data merupakan kumpulan informasi bermanfaat yang diorganisasikan ke dalam aturan yang khusus. Informasi ini adalah data yang telah diorganisasikan kedalam bentuk yang sesuai dengan kebutuhan seseorang. Menurut Encyclopedia of Cumputer Science and Engineer, para ilmuwan di bidang informasi menerima definisi standar informasi yaitu data yang digunakan dalam pengambilan keputusan[10].

\section{Oracle}

Oracle merupakan software database yang banyak dipakai perusahaan-perusahaan besar diseluruh dunia saat ini. Software ini juga banyak diminati oleh para konsultan pembuat aplikasi yang berkaitan dengan database. Sistem keamanannya yang handal membuat para profesional yang berkecimpung dalam dunia database lebih memilih Oracle sebagai perangkat untuk menunjang kegiatan bisnis mereka[11].

Disamping sistem security yang handal, Oracle merupakan software database yang bisa menampung serta mengelola data dengan kapasitas yang sangat besar serta dapat mengaksesnya dengan sangat cepat pula. Sintak SQL nya yang hampir seluruhnya memenuhi standar ANSI-92 lebih memudahkan programmer database dalam membangun aplikasi baik dari sisi back end maupun dari sisi front end. Demikian pula bagi seorang administrator yang berkecimpung dalam menangani administrasi database serta bertanggung jawab terhadap keamanan database akan merasa diuntungkan serta dimudahkan dengan software Oracle yang lebih establish ini.[12][13]

Namun demikian karena harganya yang relatif lebih mahal maka Oracle kebanyakan hanya bisa dibeli oleh perusahaan ataupun konsultan yang mempunyai dana cukup besar pula.

\section{PL/SQL}

PL/SQL (Procedural Language extensions to SQL) adalah sebuah teknologi dari Oracle yang memperbolehkan programmer untuk membuat sebuah blok program dalam Oracle sebagaimana layaknya dalam bahasa pemrograman prosedural seperti C, Fortran, COBOL dan lainnya. Tanpa adanya PL/SQL, oracle harus melakukan proses eksekusi terhadap statmen-statmen SQL sekali dalam setiap waktu. Hal ini tentu akan menyebabkan apabila program atau aplikasi client hanya menggunakan SQL murni maka program tersebut akan melakukan pemanggilan yang berulangulang kedalam database server dan ini tentu akan menurunkan performa, terutama dalam masalah kecepatan pengaksesan data yang dihasilkan[11].

Sedangkan dengan menggunakan PL/SQL, aplikasi dapat mengirimkan beberapa (sekumpulan) statemen kedalam database secara langsung dalam sekali waktu, ini tentu akan mereduksi waktu perjalanan di dalam suatu jaringan yang terjadi antara database server dengan aplikasi client.

Sekarang apabila kita membuat prosedur atau fungsi di dalam database, atau yang lebih dikenal dengan stored procedure/stored function, maka aplikasi cukup melakukan pemanggilan saja dan menunggu hasil yang diberikan oleh database. Dalam dunia pemrograman, pemanggilan prosedur semacam ini sering dinamakan dengan RPC (Remote Procedure Call). Ini jauh akan lebih efisien bila dibandingkan dengan kedua bentuk di atas. Hal tersebut dapat digambarkan sebagai berikut. [14][15]

\section{UML (Unified Modeling Language)}

UML (Unified Modeling Language) merupakan tujuan umum dari bahasa pemodelan visual yang digunakan untuk menspesifikasikan, memvisualikasikan, membangun dan sebagai dokumentasi dasar dari sebuah sistem perangkat lunak[16]. UML merupakan sebuah bahasa pemodelan standar yang digunakan untuk perangkat lunak dan perancangan sistem, sebuah bahasa pemodelan dapat dirubah kedalam pseudo-code, kode sebenarnya, gambar, diagram, atau sebuah kalimat deskriptif. Faktanya UML dapat dengan mudah mendeskripsikan sistem yang dibuat[17].

Dari beberapa definisi yang telah dijabarkan sebelumnya dapat disimpulkan secara sederhana bahwa UML (Unified Modeling Language) adalah sebuah bahasa yang menggunakan sebuah gambar, diagram atau grafik yang 
P-ISSN: 2656-7377 || E-ISSN: 2714-8467 menggambarkan sebuah perancangan perangkat lunak atau sistem, sehingga dapat dimengerti oleh orang lain dengan mudah.

\section{Pengembangan Sistem}

Pengembangan sistem merupakan sebuah prosedur yang harus dilakukan didalam sebuah sistem. Hal ini bertujuan agar sistem yang sedang berjalan dapat terus digunakan dan mengikuti perkembangan teknologi. Sebuah sistem akan disebut efektif jika bisa memenuhi seluruh kebutuhan yang menjadi pokok utama dalam pengembangan sistem itu sendiri. Berdasarkan syarat sistem informasi yang baik maka tujuan pengembangan sistem[21]

Pola perkembangan suatu sistem pada umumnya memiliki suatu pola yang sering disebut sebagai Daur Hidup Pengembangan Sistem (System Development Life Cycle). Daur hidup pengembangan sistem adalah daur dari suatu perkembangan sistem informasi mulai dari tahap perencanaan, analisis, rancangan dan tahap penerapan serta tahap penggunaan[22][23].

Untuk menghindari kerugian yang diakibatkan sistem yang usang, maka pengembang melakukan pendekatan pengembangan sistem sehingga waktu yang diperlukan untuk menerapkan sistem dapat dipangkas. Terdapat dua metode modifikasi yang paling populer digunakan, yaitu metode Prototyping dan metode Rapid Application Development (RAD).

a. Prototyping

Prototyping adalah proses menghasilkan sebuah ide atau gagasan bagi pembuat maupun pemakai peotensial tentang cara sistem yang akan berfungsi dalam bentuk lengkapnya[22]. Terdapat dua jenis prototype yaitu dimana sistem prototipe yang dibuat akan menjadi sistem yang berkelanjutan atau permanen, sedangkan yang kedua yaitu sistem yang hanya menjadi model yang nantinya akan digantikan oleh sistem yang sebenarnya dengan menerapkan elemen-elemen penting pada sistem model.

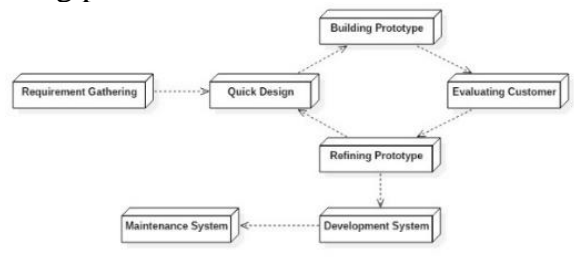

Gambar. 1 Model Prototyping

b. Rapid Application Development (RAD)

RAD adalam seperangkat strategi, metodologi dan peralatan yang terintegrasi yang dala dalam satu kerangka kerja yang disebut juga information engineering[23]. Dalam proyek RAD terdiri dari empat tahap yaitu tahap perencanaan kebutuhan sisem, tahap desain pengguna, tahap konstruksi, dan tahap penyerahan.

\section{ANALISIS DAN PERANCANGAN}

\section{Analisis Sistem}

Analisis sistem adalah sebuah langkah pemecahan suatu sistem yang utuh kedalam kelompok bagian tertentu dalam rangka melakukan pendefinisan dan evaluasi permasalahan, hambatan, peluang dan kebutuhan yang ada didalam sebuah sistem, sehingga dapat dilakukan proses pembaharuan atau perubahan didalam sistem. Analisis sistem di lakukan untuk mengetahui permasalahan apa yang sedang terjadi di dalam sistem sebuah perusahaan yang kemudian hasil dari analisis sistem tersebut digunakan sebagai dasar acuan sebagai pembanding dan sebagai dasar pembuatan sistem alternatif yang baru.

a. Prosedur yang Sedang Berjalan

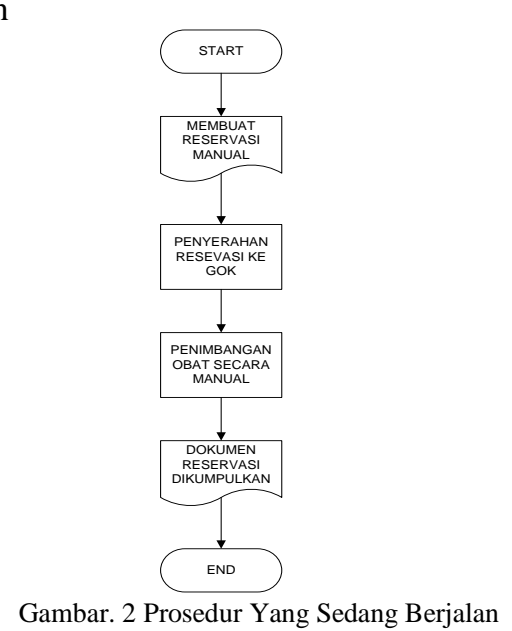


P-ISSN: 2656-7377 || E-ISSN: 2714-8467

Gambar 2 menjelaskan bahwa para operator mesin di area Processing baik divisi Pencelupan atau Printing melakukan permohonan permintaan obat menggunakan sebuah formulir standar yang di isi secara manual. Data yang diisikan kedalam formulir tersebut berupa obat atau chemical apa yang akan digunakan dan berapa kuantiti yang diperlukan, untuk mendapatkan nilai kuantiti yang diperlukan para operator harus menghitung secara manual menggunakan alat hitung konvensional berdasarkan rumus atau aturan baku yang telah di tetapkan oleh pihak yang membuat resep.

Setelah formulir tersebut dibuat dan di tandatangani oleh kepala seksi yang bertugas, kemudian formulir tersebut diberikan kepada petugas gudang obat kecil yang kemudian membuat pesanan operator produksi dan menyimpan bukti permintaan obat yang kemudian disetorkan kepada pihak administrasi gudang obat kecil.

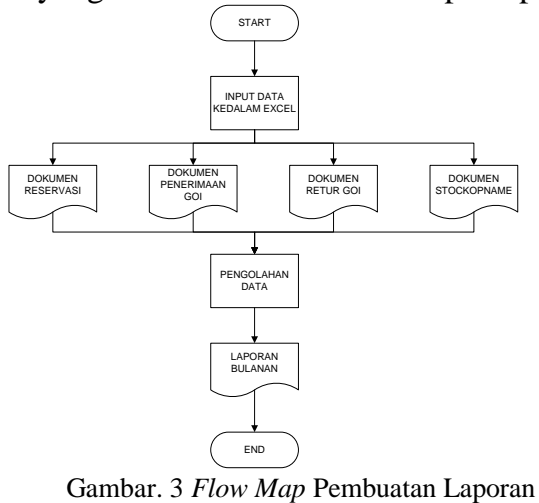

Dari gambar 3 dapat dijelasakan bahwa setelah formulir diserahkan kepada petugas administrasi gudang obat kecil, langkah selanjutnya adalah melakukan rekapitulasi data yang terdapat didalam formulir secara manual kedalam program excel yang digunakan sebagai dasar acuan pengeluaran gudang. Selain dari transaksi pengeluaran ke are produksi processing, gudang obat kecil pun melakukan transaksi penerimaan obat/chemical dari gudang obat induk yang dimana data dari formulir penerimaan nantinya akan kembali direkapitulasi kedalam program excel yang digunakan sebagai dasar acuan penerimaan gudang. Selain transaksi penerimaan dan pengeluaran, gudang juga memiliki tanggung jawab melakukan stock opname setiap akhir bulan sebagai dasar transaksi sisa stok digudang yang nantinya akan dilakukan penyeimbangan/balancing dengan transaksi keluar dan masuk di gudang obat kecil.

b. Perancangan Sistem

1. Use case Diagram

Use case Diagram ini digunakan sebagai gambaran umum tentang bagaimana sistem akan bekerja secara lengkap. Berikut ini merupakan gambaran besar tentang sistem yang akan dibuat.

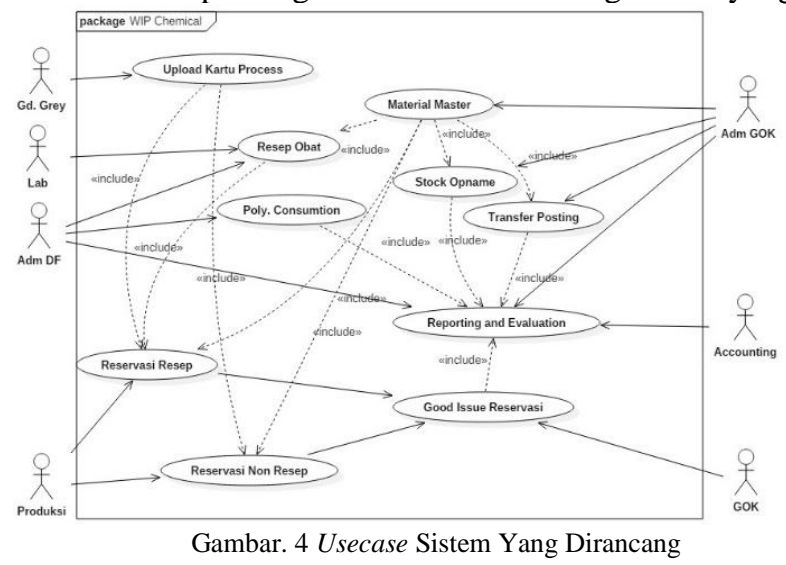

Use case diagram lengkap diatas memiliki setidaknya tujuh aktor utama yang dilambangkan dengan simbol orang dan memiliki label pada bagian bawahnya yang berfungsi sebagai identitas masing-masing pengguna. Berdasarkan gambar diatas maka setidaknya terdapat sedikit gambaran bagaimana sistem yang akan dibuat akan bekerja dan setiap pengguna memiliki fungsi dan tugas masing-masing didalam sistem.

c. Perancangan Prosedural

Perancangan prosedural merupakan perancangan prosedur kerja sistem yang akan dibangun. Sebuah prosedur sangat dibutuhkan dalam sebuah sistem, dikarenakan prosedur merupakan batasan atau panduan sistem dalam bertindak atau dalam bertingkah laku. 
NARATIF(Jurnal Ilmiah Nasional Riset Aplikasi dan Teknik Informatika)

Vol. 03 No. 01 Juni 2021

P-ISSN: 2656-7377 || E-ISSN: 2714-8467

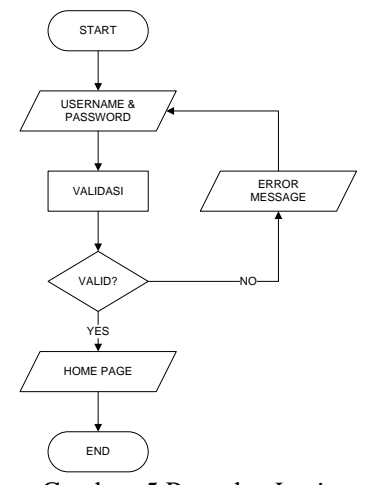

Gambar. 5 Prosedur Login

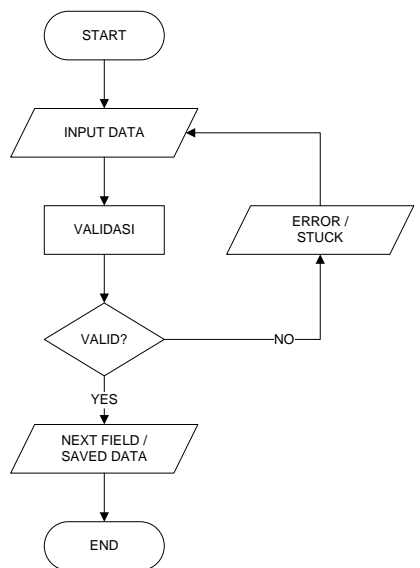

Gambar. 6 Prosedur Penambahan Data

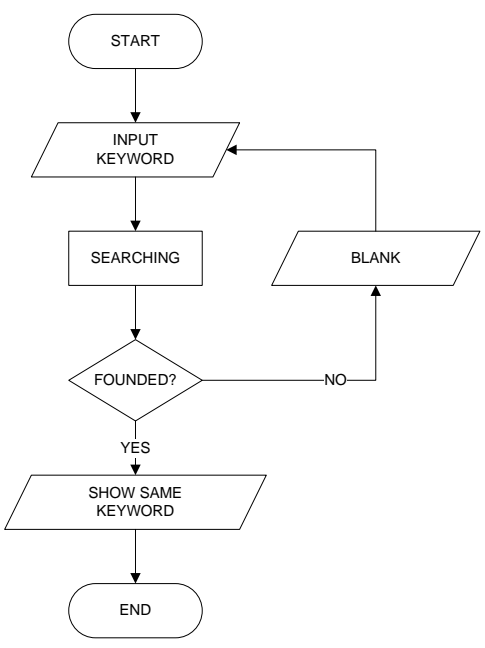

Gambar. 7 Prosedur Pencarian Data

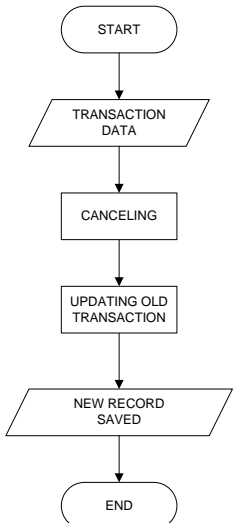

Gambar. 8 Prosedur Pembatalan Transaksi 


\section{KESIMPULAN}

Setelah proses penelitan, analisis hingga pengujian sistem dilakukan maka diperoleh kesimpulan sebagai berikut :

1. Teknologi informasi dimanfaatkan dalam proses transaksi gudang beserta seluruh laporannya menggunakan aplikasi yang dibuat. Seperti diantaranya Reservasi, Laporan persediaan, Perhitungan stok barang secara sistem dan Perhitungan evaluasi caustic

2. Informasi yang diinginkan oleh pihak manajemen atau pihak terkait dapat dikeluarkan berdasarkan laporan yang diinginkan dengan kondisi isi laporan sesuai dengan transaksi yang terjadi sesuai periode yang diinginkan.

3. Seluruh data transaksi disimpan kedalam satu buah server yang memiliki kapasitas 500Gigabyte dengan perkiraan dapat menampung data hingga lebih dari 5 tahun. Sehingga mengurangi penggunaan tempat untuk penyimpanan arsip.

\section{REFERENSI}

[1] Sutabri T. SISTEM INFORMASI MANAJEMEN. Yogyakarta: ANDI; 2016.

[2] O’Brien, Marakas. Management System Information. New York: McGraw Hill; 2010.

[3] Kadir A. Pengenalan Sistem Informasi. Am Enterp Inst Public Policy Res 2014:1-19. doi:10.13140/2.1.2637.6328.

[4] Anggadini SD. Analisis Sistem Informasi Manajemen Berbasis Komputer dalam Proses Pengambilan Keputusan. Maj Ilm Unikom 2013;11:17687.

[5] Bahasa P. Kamus Besar Bahasa Indonesia. Pus Bhs n.d. http://kbbi.web.id.

[6] McLeod R. Sistem Informasi Manajemen 2007.

[7] Darmawan D. SISTEM INFROMASI MANAJEMEN. UPI PRESS; n.d.

[8] Jogiyanto Hartono. Sistem Informasi Manajemen 2013:114.

[9] Sutono D. Sistem Informasi Manajemen. KT SIM 2007.

[10] Dzacko H. Basis Data (database). J Basis Data ICT Res Cent UNAS 2007;5:1-28.

[11] Heryanto I, Raharjo B. Menguasai Oracle dan PL/SQL. Edisi Ke 2. Bandung: INFORMATIKA; 2009.

[12] Fathansyah. Basis Data. Bandung: INFORMATIKA; 1999.

[13] Beaulieu A, Mishra S. Mastering Oracle SQL. O’Reilly; 2002.

[14] Pribyl B. Learning PL/SQL. O’Reilly; 2001.

[15] Corporation O. Oracle 10g PL/SQL User's Guide and Reference 2003.

[16] James R, Jacobs I, Booch G. The Unified Modeling Language Reference Manual. ADDISON WESLEY LONGMAN, Inc.; 1999.

[17] Miles R, Hamilton K. Learning UML 2.0. Safari; 2006.

[18] Syafei H. OBJECT ORIENTED MODELLING WITH UNIFIED MODELING LANGUAGE ( UML ) 2016. doi:10.13140/RG.2.1.3464.4088.

[19] Anharku. Flowchart 2009:1-4.

[20] Barakbah AR, Karlita T, Ahsan AS. Logika dan algoritma. Politeknik Elektronika Negeri Surabaya; 2013.

[21] Sutabri T. Sistem Informasi Akuntansi. Yogyakarta: ANDI; 2004.

[22] Kusumah AI. Pengembangan sistem dalam sistem informasi akuntansi 2011:6-15.

[23] McLeod R, Schell G. Sistem Informasi Manajemen. Kedelapan. JAKARTA: PT. Indeks; 2004. 